\title{
Youth Media Lifestyles
}

Claudia van Kruistum, Paul P.M. Leseman, and Mariëtte de Haan

Department of Pedagogical and Educational Sciences, Utrecht University, Heidelberglaan 1, 3584 CS Utrecht, The Netherlands

Author Note

This is the peer reviewed version of the following article: Kruistum, C. van, Leseman, P.P.M. \& De Haan, M. (2014). Youth media lifestyles. Human Communication Research, 40(4), 508-529, which has been published in final form at http://dx.doi.org/10.1111/hcre.12033. This article may be used for non-commercial purposes in accordance with Wiley Terms and Conditions for self-archiving.

This research has received the financial support of the Dutch Program Council for Educational Research (PROO) of The Netherlands Organization for Scientific Research (NWO), file nr. 411-06-502.

Correspondence concerning this article should be addressed to Claudia van Kruistum, Department of Research and Theory in Education, VU University Amsterdam, Van Der Boechorststraat 1, 1081 BT Amsterdam, The Netherlands. E-mail: c.j.van.kruistum@vu.nl 


\begin{abstract}
In this paper the concept of 'media lifestyles' is adopted in order to develop a comprehensive approach towards youth engagement in communication media. We explore how 503 Dutch eighth grade students with full access to new technology combine a broad range of media by focusing on their engagement with media while taking various contexts of use into account. Four different media lifestyles of media omnivores, networkers, gamers and low-frequency users are described. Furthermore, we show how the methodology we used is able to provide more insight into how the distinguished media lifestyles were co-determined by particular media, functions and social contexts. Finally, the implications for the Uses \& Gratifications theory are discussed.
\end{abstract}

Keywords: media, functions, social context, youth, cluster analysis, facet design 


\section{Youth Media Lifestyles}

Young people are often claimed to be different from those born before the advent of the Internet in their familiarity with and use of technologies, and thus referred to with terms as 'the Net Generation' or 'Digital Natives'. However, to view new media engagement as something that defines a generation runs the risk of oversimplification and obscures the differences that exist among youth in the ways they use and combine different communication media, old and new. This study adopts the concept of 'media lifestyles' from Livingstone and Bovill (1999) who have argued that youth differ in the ways they structure their leisure time, balance options and put together meaningful combinations of activities to suit specific interests. A media lifestyle arises from the interplay between possibilities afforded by the medium, access to media, the social context, existing leisure practices and personal preferences. Each young person weaves together a huge diversity of activities in a unique way. While some choices may be more deliberate than others, every choice is meaningful by virtue of its relationship to each of the aspects mentioned above.

The purpose of the present study is to describe the diversity of media lifestyles adopted by youth who have full access to new media while old options remain available to them. We use a more comprehensive and complex methodology than former studies in order to study young people's engagement in a very broad range of media while taking the contexts of use into account. Thus, our study contributes to existing research in three distinct ways. First, we adopt a broad perspective on engagement with media that is underrepresented in current research, as it includes traditional print-based media as well as new media, typically associated with digital media such as computers and mobile phones. Our study also incorporates face-to-face interaction, which we consider a medium of communication, albeit not a technological medium. Second, our study was conducted in The Netherlands, where virtually all youth have home Internet access and own a mobile phone (Duimel \& De Haan, 
2007), in contrast to countries such as the US where the spread of new media appears to proceed at a slower rate (Rideout, Foehr \& Roberts, 2010). This allows us to explore the question which media lifestyles youth adopt when availability of mobile phones and computers with Internet access is not at issue. Third, particularly unique to our study is the design that was drawn upon to systematically relate media engagement to various contexts of use. This approach is relevant to get more insight into how media lifestyles come into existence, namely whether the use of one medium might be related to another, what the role of the underlying technology is, and to what extent media choices follow from personal preferences.

\section{Perspectives on the Relationship between User and Technology}

The issue of how media lifestyles come into existence is rooted in a more fundamental debate regarding the relationship between a technology and its user. Katz (1959) proposed that there are two ways of viewing this relationship, namely to ask oneself what media do to people (a techno-centred perspective) or to question what people do with media (a functional perspective). He and many with him have advocated the latter position, suggesting that people's values, interests, associations and social roles are pre-potent; people selectively fashion what they see and hear to their interests (cf. Heath, 1980; Herring, 2008; Hine, 2005). This belief is at the heart of the Uses and Gratifications (U\&G) approach, which holds that media use is goal-directed, purposive and motivated (Rubin, 1994). In addition, this perspective shifts the focus from the effects of particular media to the connections people make among dispersed media content, since people seek out functional alternatives in the larger media landscape. As Jenkins (2006: 2) puts it, audiences "will go almost anywhere in search of the kinds of entertainment experiences they want".

Several objections have been offered against the assumptions underlying the $U \& G$ approach as well as against how these have worked out in actual research. First, to emphasize 
the malleability of technology is to understate the importance of opportunities that are created as well as the limits that are set by inherent properties of particular technologies. For instance, Buckingham (2008) argues that technology is not simply a matter of what people choose to make of it; technologies have inherent affordances which make it easier to use them for some purposes rather than others. He, as others before him have (e.g., Williams, 1974), therefore unifies a techno-centred perspective with a functional standpoint, recognizing that technology is both socially shaped and socially shaping.

Second, within U\&G a large emphasis is placed on needs, motives and gratifications rather than on the actual use of technologies. Moreover, the underemphasized 'use' component is commonly treated as 'media exposure', which is a very important difference carrying theoretical and methodological consequences, as Petrič, Petrovčič and Vehovar (2011) show. While it may make sense to speak of exposure when dealing with mass media, a different perspective is required for interpersonal communication media, which essentially involve social interaction between interlocutors. This is a major point considering the rise of social media, which have come to coexist with and transform mass media uses and have much in common with face-to-face interaction.

Third, while it is in theory recognized by those adopting a functional point of view that media compete with each other and that people make connections across media that are somehow relevant to them, actual research mostly focuses on a very restricted range of media and media applications. For example, very little $U \& G$ research has addressed the issue of choosing new communication technologies in conjunction with old ones (as argued by Flanagin \& Metzger, 2001; Petrič et al., 2011). Others have shown before that, thus, fundamental continuities and interdependencies between newer and older media are neglected (cf. Bolter \& Grusin, 1999; Buckingham, 2008; Lister et al., 2003). Furthermore, in recent critiques it is stressed there has been a tendency within $U \& G$ research to focus on 
entertainment and enjoyment gratifications at the cost of more serious, cognitively demanding media experiences (Oliver and Bartsch, 2010; Wirth, Hofer \& Schramm, 2012). So a broader conceptualization of media use is required to fully capture the different needs and interests driving engagement in old and new technologies.

To summarize, researchers have long established that technologies and the uses to which they are put are intertwined. However, there is a lack of empirical studies with a broad focus showing how people make meaningful combinations of media, old and new, and how different functional and social needs may be related to their choices for particular media. We use the previously mentioned concept of 'media lifestyles' from Livingstone \& Bovill (1999) to deal with the critiques discussed previously, as it allows us to recognize that technology may have a shaping influence on a person's engagement with media along with other factors such as the variety of functions and social relations involved. In order to implement it in research, we adopt a person-centred quantitative approach, thereby shifting the focus from media uses to media users. Results from studies adopting this method are discussed in the next paragraph.

\section{Media Lifestyles and their Origins: Insights from Research}

A method regularly adopted to investigate how youth combine media, thus revealing different media-use styles, is cluster analysis. This is a technique that groups cases that are more 'similar' to each other than they are to cases in other clusters, meaning that subjects with similar responses across variables are grouped together (Fielding, 2007). Results from studies drawing upon cluster analysis to study youth media uses have indicated that there are roughly those who use media infrequently (low-frequency users), those who regularly use a broad range of media applications (omnivores), and those who are more focused on, often even specialized and intensely committed to, one particular media use (specialist users). Specialist users spend large amounts of time on either books, magazines, computer games or 
social media (Brozo, Shiel \& Topping, 2009; Livingstone \& Bovill, 1999; Van den Beemt, 2010). Media omnivores combine a range of new media applications (Van den Beemt, 2010), read several types of print-based media (Brozo et al., 2009), or compose a mix of print and screen media (Leino, Linnakylä \& Malin, 2004; Livingstone \& Bovill, 1999). Low-frequency users are youth who are not major users of any one medium (Livingstone \& Bovill, 1999). These cluster-analytic studies have in common that their focus is primarily on the technology as the explanatory factor, in most cases on either new technology or print-based media. Moreover, they leave untouched the issues why youth do or do not combine certain media and in which contexts such connections arise. Consequently, the question remains how media lifestyles come into existence, whether the use of one medium might be related to another and what the role of (access to) the technology is.

Taking these issues into account is even more important given that there are indications that an intricate relationship exists between media lifestyles and offline behaviour and preferences. Following-up on their cluster-analytic study, Livingstone \& Bovill (1999) found that youth made combinations - of different types of media as well as between media and unmediated actions - which were prompted by a certain interest. For instance, they observed that sports and music featured in a range of media and also stimulated outside events such as football matches and discos. In a more recent study Ito, Horst, Brittanti et al. (2008) showed how youth brought their offline interests and social contacts to their online media activity. Results from this study suggest that the majority of youth used new media to sustain existing relationships, which corroborates previous research findings (also see Boase, Horrigan, Wellman \& Rainie, 2006; Boneva, Quinn, Kraut, Kiesler \& Shklovski, 2006). In this type of engagement existing offline practices of hanging out with friends were largely replicated through new media. Ito et al. (2008) also observed that there was a minority of 'geeks' who were intensely committed to new media and were focused on gaining deep 
knowledge and expertise in specific areas of interest. These youth were involved in complex forms of gaming, movie making or writing fan fiction, to name some examples. Their particular interest was often sparked offline and then further pursued online on their own initiative. However, not under all circumstances were youth able to bring offline interests to online media activity. Especially intense forms like 'geeking out' required (ongoing) access to media, the time and freedom to explore and experiment, as well as a social network that supported interests and facilitated required skills and knowledge. In other studies access to media and a supportive social environment have been found to be enabling factors as well (Eastin, Greenberg \& Hofschire, 2006; Livingstone \& Bovill, 1999; Roberts \& Foehr, 2008). In sum, research findings show that it is meaningful to adopt a perspective on media engagement that includes offline contexts. Given the right conditions, youth are likely to bring their offline behaviour, interests and relationships to their media activity. However, it is not exactly clear to what extent youth do so. Do they involve a broad range of media or only particular kinds? Is their media mix directed towards a particular use or are youth more broadly oriented? And how does this differ for particular groups of youth?

\section{The Present Study}

In the present study we set out to describe the media lifestyles of youth with full access to new technology. Moving beyond the restricted range of media usually incorporated in empirical studies, our study included new media, traditional print-based media and also face-to-face (offline) interaction. In order to gain more insight into how these media were used and combined by youth, we designed our study such that we could relate each medium to different contexts of use. This way we methodically explored both the more interest-driven aspects of media engagement (e.g., for entertainment or to gain knowledge) as well as those that were primarily friendship-driven (i.e., involving people known intimately). In order to identify media lifestyles, youth using similar media within similar contexts were grouped. 
This procedure allowed us to distinguish, for instance, a media lifestyle characterized by high involvement in one medium or several media for social reasons (function) with people known intimately (social distance), from a media lifestyle driven by a particular interest (function) involving distanced others (social distance).

The setup of our study enabled us to address not only the role of the technology, but also how a particular function or social distance or a combination between these was represented throughout the broad media spectrum. Compared to the cluster-analytic studies reported upon in the previous paragraph, we expected to obtain more insight into the combinations youth made (or did not make) of a broad range of media while taking various contexts of use into account. As gender is known to strongly influence media preferences (see, for instance, Ünlüsoy, De Haan, Leseman \& Van Kruistum, 2010), we checked whether differences existed between boys and girls with regard to their media lifestyles. Because the present study was performed in The Netherlands, which has a tracked educational system, we also compared the media lifestyles of youth from lower tracks to those from higher tracks. Finally, as we noted earlier, the youth under investigation in this study had ready access to new media. This allowed us to assess whether equal opportunities resulted in equal media uses by boys and girls and youth from lower and higher tracks respectively.

\section{Method}

\section{Sample}

The sample consisted of 503 Dutch students in their second year of secondary education (grade 8) with a mean age of 13.7 years. Of these students, $267(53.1 \%)$ attended the lower tracks of secondary education (prevocational secondary education, i.e., the Dutch $v m b o$ ) and $236(46.9 \%)$ the higher tracks (senior general secondary education and preuniversity education, i.e, havo and $v w o$ ). There was a discrepancy between the number of boys and girls in both tracks. In the lower educational tracks there were more boys $(55.8 \%)$, 
whereas in the higher tracks there were more girls (53.0\%). The sample was representative for schools in urban regions of The Netherlands, including the uneven gender distribution (Centraal Bureau voor de Statistiek, 2009). At the time the research was conducted virtually all students had access to the new media under investigation, as 490 students (97.4\%) indicated to own their own mobile phone and 498 students $(99.0 \%)$ to have home Internet access.

\section{Procedure}

After a pilot with 46 students from lower and higher educational tracks, data collection took place in the spring of 2009. Students filled out a media activities questionnaire individually via the study's website. The questionnaire was administered in a school classroom with a researcher or assistant and a teacher present on-site. Username and password were provided by the researcher. Before starting, the researcher gave instructions and monitored whether students were able to $\log$ in. On average it took subjects 29 minutes to fill out the questionnaire.

\section{Design of the Questionnaire}

The media activities questionnaire was designed in accordance with Guttmann's Facet Theory, which offers a systematic approach to the measurement of a complex phenomenon like media engagement (Guttman \& Greenbaum, 1998). First, multiple dimensions, or facets, of that phenomenon are defined and then combinations of the facets are used to guide the construction of the measurement instrument such that each facet combination is represented by at least one questionnaire item. We focused on three facets of media engagement, as mentioned in the introduction. As such, the facets represent rather abstract properties of the broad media engagement concept, but once combined they enable a more fine-grained description of several types of media activities. Here we give a brief description of the facets. 
For a more thorough discussion as well as more detailed information regarding the procedure we followed, we refer the reader to Van Kruistum, Leseman, De Haan (2014).

The first facet, medium, was divided into four categories: (1a) face-to-face contact, (1b) print-based media, (1c) asynchronous new media, and (1d) synchronous new media. These distinctions roughly follow the historical development of media and communications, moving from oral to printed communication and, more recently, from electronic to digital media (see Rantanen (2005) for an in-depth argumentation). Examples of media incorporated in the questionnaire were real-life conversation (face-to-face), magazines, books, newspapers, notes, letters, postcards (generally print-based, but also including hand-written materials), email, social network sites, photo-editing software, YouTube clips, television (asynchronous new media), Instant-Messenger, webcams and multiplayer online games (synchronous new media). As we explained previously, these categories are heterogeneous when considered in isolation. However, each of them was systematically combined with subcategories of other facets, thus providing a very nuanced description of media engagement along multiple dimensions. For example, television and social network sites were both categorized as asynchronous new media, but they were distinguished from each other through the second facet.

By means of the second facet, social distance, we roughly distinguished (2a) a small social distance, as between friends or close relatives, from (2b) a large social distance, as between a teacher and a student or an author and his audience. Finally, in case of the third facet we contrasted two main function types, namely (3a) an epistemic function, and (3b) a social-entertainment function. Media engagement could occur to keep in touch (social), to relax (entertaining) and to gain knowledge or creatively express oneself (epistemic). The functions social and entertainment, both aimed at more immediate goals such as seeking enjoyment and intimacy, were combined in order to contrast them with the cognitively more 
demanding epistemic functions, which are highlighted in recent U\&G research (e.g., Oliver \& Bartsch, 2010; Wirth et al., 2012).

Systematically combining all facet categories yielded 16 possible combinations $(4 \times 2 \times 2)$, henceforth labelled 'media practices'. In total 33 items were constructed of which the pilot study had shown that they were relevant to and representative of the life world of the youth under investigation, as well as recognizable to them as realistically occurring situations. Typical questionnaire items were 'Do you talk to friends or family members about global issues, such as politics or the environment?', 'Do you read magazines for enjoyment, for example about fashion or computer games?', 'Do you instant-message with friends or family members to keep in touch?' and 'Do you browse the web to be informed about current events?'. The complete list of items is included in the appendix. For each questionnaire item respondents were asked to estimate the frequency and/or duration of engagement, which was measured on a seven-point scale with (1) representing never, (2) less than once a month, (3) at least once a month, (4) at least once a week, (5) (almost) every day, (6) 1-2 hours a day, (7) more than two hours a day.

\section{Analysis Strategy}

The main goal of the present study was to give a description of youth media lifestyles including contexts of use. We defined a media lifestyle as a group of youth with similar combinations of media practices. In the results section, we will first provide scores indicating frequency/duration of engagement in the media practices. Differences between boys and girls and youth from lower and higher educational tracks are also reported, which were tested by means of two multivariate ANOVA's. Next, we will discuss the results of the cluster analysis that was performed to identify media lifestyles. We adopted a procedure outlined in Fielding (2007) in which the commonly used $k$-means algorithm is combined with a hierarchical clustering method to find the best partitioning, in our case a four-cluster solution. In addition, 
differences between the clusters are reported, which were tested by means of a MANOVA and followed up by post-hoc tests. Finally, an overview is presented of the number of youth from lower and higher tracks and boys and girls within each cluster, including results from chi-square tests that were performed to examine differences.

\section{Results}

Descriptive statistics of the media practices are presented in Table 1 for the entire group and the lower and higher educational tracks and boys and girls separately. These descriptive statistics show the means and the standard deviations of young people's engagement with a particular medium for a particular function involving a particular social distance, denoted as a 'media practice'. The scale that was used ranged from a minimum of (1) never to a maximum of (7) more than two hours a day. Also included in Table 1 are results from the MANOVA's that were performed to compare the tracks and genders, showing how large differences were between boys and girls and youth from lower and higher tracks with respect to their engagement in a particular media practice. Partial eta squared is reported as an effect size.

\section{[Table 1]}

A cluster analysis was performed to group youth with similar responses across media practices. Four clusters or lifestyles emerged from the analysis, each of which will be characterized in the following subparagraphs. Mean engagement in the media practices and the standard deviations are once again provided, this time for each of the four clusters (see Table 2). Comparisons between clusters are also shown, indicating how large differences were between the clusters with respect to their reported engagement in a particular media practice. The means from Table 2 are graphically depicted in Figure 1.

[Table 2]

[Figure 1] 
In Table 3 an overview is presented of the number of youth from lower and higher tracks and boys and girls within each cluster, including results from the chi-square test that show how large differences were between expected and observed numbers. Cramer's $V$ is reported as an effect size. Finally, in order to provide more detailed descriptions of the clusters in the following subparagraphs, we have included a characterization of the media engagement prototypical of a young person within a certain cluster. We used a score obtained from the cluster analysis indicating distance of a case from its classification cluster centre to assess which subjects were most prototypical of each cluster. The mean scores of prototypical cluster members on each media practice are also graphically presented in Figure 1. The names used are fictitious.

\section{[Table 3]}

We found significant differences between the four clusters for their reported engagement in the media practices (Wilk's Lambda $=.06 ; F(39,1442.86)=57.58 ; p<.001$; partial $\eta^{2}=.60$ ). Table 2 shows that the differences between clusters were largest for synchronous new media with distant others for social-entertainment purposes (practice $J$, i.e., multiplayer online gaming), followed by face-to-face contact with known others for epistemic purposes (practice $B$, e.g., visiting the theatre) and synchronous new media with known others for social-entertainment purposes (practice $H$, e.g., instant-messaging). As can be seen from Table 3, expected and observed population numbers differed statistically significantly for gender and educational track, but the effect was stronger for gender. It was also investigated whether the number of youth from lower and higher tracks and boys and girls observed within each cluster deviated significantly from the number expected based on the proportion of youth from lower/higher tracks, and boys/girls in the entire sample. These outcomes will be discussed for each cluster separately. 


\section{Cluster 1 - Omnivores: Appropriating All Media for Multiple Functions in}

Diverse Social Contexts. A girl named Anna was a prototypical member of the first cluster. She indicated that she frequently engaged in oral conversations with friends, not only to talk about events related to daily life $(A)$ but also to discuss global issues $(B)$, for instance about politics or the environment. She read print media such as books, newspapers and magazines on a regular basis and did so mostly for enjoyment $(F)$ but also to learn something or to be informed about current events $(G)$. Her engagement in these print-based media did not preclude engagement in new media. She used synchronous new media like instant-messaging to keep in touch with friends $(H)$, but not as much as her peers. Furthermore, she used asynchronous new media $(K-M)$ frequently, for example to browse the web for educational information, watch YouTube clips for enjoyment and keep in touch with friends by means of her online profile and text-messaging. However, she was not at all involved in multiplayer online gaming $(J)$.

Anna and others in the first cluster were versatile, all-round media users, meaning that they used a broad range of media for different functions in diverse social contexts. We therefore labelled them omnivores. There were more girls and youth from higher tracks in this cluster than expected based on their count in the entire sample, and fewer boys and youth from lower tracks. Omnivores appeared to be especially adept at appropriating possibilities

offered by new technology, but without disconnecting from face-to-face interactions or printbased media and without specializing in a particular media use. A striking exception to this pattern was their disengagement from multiplayer online gaming, which indicates that this media practice did not combine easily with their all-round media lifestyle.

\section{Cluster 2 - Networkers: Staying Connected with Known Others across Offline}

and Online. A prototypical member of the first cluster, Michelle, often had oral conversations with people she knew well to talk about events of everyday life $(A)$. She reported to use 
synchronous new media in this particular context $(H)$ almost as much, for instance by instantmessaging or using a webcam. Furthermore, she often drew upon asynchronous new media to keep in touch with friends and relatives $(K)$, for example her online profile and her mobile phone for text-messaging. However, the differences between her and youth from other clusters were smaller for the asynchronous than the synchronous new media. Overall, Michelle's media engagement was hardly motivated by epistemic goals. For instance, although she frequently engaged in oral conversation, especially with friends and relatives, this conversation typically did not concern global issues $(B)$.

Michelle had a strong preference for one particular media use, namely to keep in touch (social-entertainment function) with friends and relatives (small social distance). We therefore labelled her and others in her cluster networkers. There were more girls and fewer boys than expected in this cluster given their count in the larger sample. Based on expected frequencies, no significant differences were found between the number of youth from lower and higher tracks. Interestingly, networkers stayed connected with known others through face-to-face interaction and new media, but without including print-based media like letters, notes and postcards. This suggests that besides the functional and social context, the technology was of importance as well.

Cluster 3 - Gamers: Specializing in a Medium for Entertainment within a Distant Social Context. Mark, who was representative of the third cluster, reported to spend much of his time engaging in synchronous new media with distant others for social-entertainment functions $(J)$, namely playing multiplayer online games such as Second Life or World of Warcraft. His engagement in online gaming was higher than engagement in any other media practice. Furthermore, he indicated to spend a large amount of time on social-entertainment practices involving unknown others accessed through asynchronous new media $(L)$, for instance web based games, YouTube and television. In comparison to youth from other 
clusters, Mark was more often engaged in print-based practices that involved socialentertainment purposes and known others $(E)$, examples of which were writing and receiving postcards and keeping a journal. However, in this sense he formed an exception to the general pattern within his own cluster. More than Michelle (a networker), he engaged in oral conversation with friends and relatives about global issues $(B)$. And more than Anna (an omnivore) and Peter (to be introduced), he used synchronous new media like instantmessaging to keep in touch with people he knew $(H)$.

Most distinctive for the media lifestyle adopted by Mark and other members of the third cluster was their high engagement in multiplayer online gaming, and we therefore labelled them gamers. There were more boys and fewer girls in this cluster than expected from their count in the entire sample. Based on expected frequencies, no significant differences were found between the number of youth from lower and higher tracks in this cluster. Gamers' high engagement in multiplayer online games - higher than any other media practice and much higher than youth from all other clusters - suggests that this media practice exists on its own right, without having clear connections to other media practices. However, as gamers were (somewhat) less involved in a similar type of usage through asynchronous new media, this indicates that a combination of the medium (new), function (socialentertainment) and social arrangement (large social distance) drove their engagement.

\section{Cluster 4 - Low-Frequency Users: Not Bringing Offline Interests and}

Relationships Online. Being a prototypical member of the fourth cluster, Peter reported low engagement in all media practices compared to youth from other clusters. There was one exception to this trend, namely multiplayer online gaming practices $(J)$, which he engaged in more than Anna (a media omnivore) and Michelle (a networker), but less than Mark (a gamer). However, in this regard he formed an exception to the general trend within his own cluster. Peter's low involvement was especially striking for a number of media practices. In 
comparison to other youth, he did not engage in oral conversation often with friends and relatives about issues of daily life $(A)$, nor in text-messaging, e-mailing or using an online profile to keep in touch $(K)$. But Peter's engagement in these practices, especially face-to-face interaction, was relatively high considering the broad spectrum of his media engagement. Furthermore, Peter less often read books, newspapers and magazines for pleasure $(F)$ compared to his peers. Finally, he indicated to use asynchronous new media less frequently for knowledge gathering or creative expression $(M)$. Examples of such practices were reading lyrics and poems online, browsing the web to find educational information, and watching television to be informed of current events.

Because of their overall low engagement in media practices, we labelled Peter and others in the fourth cluster low-frequency users. There were more boys and fewer girls in this cluster than expected based on their count in the larger sample, but no significant differences were found between the number of youth from lower and higher tracks. Their low involvement in the broad media spectrum indicates that these youth did not bring their offline interests and relationships into regular use of any medium, be it print-based or new. Of all media practices, they were mostly oriented towards face-to-face interaction with friends and relatives.

In sum, the present study set out to describe youth media lifestyles including contexts of use. We found four clearly different media lifestyles defined in terms of (1) the medium through which a particular media activity took place, (2) the social distance involved between sender and receiver, and (3) the function of the particular activity. We were able to describe the media lifestyles of omnivores, networkers, gamers and low-frequency users in terms of how they 'behaved' across face-to-face activities and a wide spectrum of media activities, including traditional and new media.

\section{General Discussion}




\section{A Deeper Insight into Media Lifestyles}

In the introduction we argued that the concept of media lifestyles (Livingstone \& Bovill, 1999) may provide a theoretical point of departure for unifying a techno-centered with a functional perspective. In line with the idea that a media lifestyle arises from the interplay between several factors such as possibilities afforded by the technology as well as personal preferences, the present study set out to investigate how a group of Dutch eighth graders, with full access to new technology, made meaningful combinations of communication media. We moved away from former cluster-analytic studies by including a much broader range of media, including face-to-face interactions, and by systematically exploring the functions and social relations involved. With respect to the four media lifestyles that were described, our study replicates previous research findings and shows how robust particular profiles of media users are (Brozo et al., 2009; Leino et al., 2004; Livingstone \& Bovill, 1999; Van den Beemt, 2010). Yet it provides a more complex picture of the diversity of media users, as it offers insight into how the use of one medium is related to another, in particular what the role of the underlying technology is and to what extent media choices follow from a particular functional or social need.

With respect to the latter, our study suggests that differences in the need or desire to bring offline social connections to online activity play a particularly large role in how media are adopted. Previous studies have shown that the majority of youth use new media to sustain existing relationships (Boase et al., 2006; Boneva et al., 2006, Ito et al., 2008). While the present study confirms that this is a relatively important aspect of media engagement within each of the four lifestyles, it also shows that this is not a defining characteristic of the media lifestyle most youth adopt. That is, in the networkers' lifestyle online media activity was most clearly oriented towards intimate others, but the dominant media practices of gamers, for instance, were instead cultivated in a distant social context. Also, the low-frequency media 
users and the media omnivores were much less oriented towards sustaining intimate relationships compared to networkers. As such, the present study shows that while there are similarities in the relative use youth make of the different media options available to them during leisure time - suggesting that there are needs, desires, attractions and obligations most, if not all, youth of this particular age share - it is precisely against these broad similarities that significant differences become apparent in the ways youth use and combine media. Clearly, access to technology is a necessary but not a sufficient condition for youth to incorporate technology in their lifestyles. Our findings pertaining to whether youth bring their social connections online show that a study like ours may contribute to understanding what drives the individual differences that continue to exist.

As we argued in the introduction, technologies have inherent affordances (Buckingham, 2008), meaning that some media are better suited to the type of usage youth are inclined to seek. For example, networkers were more engaged in face-to-face interaction and synchronous new media to stay connected to friends and relatives compared to asynchronous new media (as well as print-based media, which was to be expected). This may indicate that technological properties of synchronous new media tap into a basic need these youth have to engage in real-time interaction with significant others - as with face-to-face interaction - and that synchronous new media are therefore preferred over asynchronous alternatives. Thus, the present study shows how media lifestyles are co-determined by individual preferences and the type of medium involved. In some cases the technology may even intensify a particular type of engagement and recreate or strengthen these preferences, as the most preferred media practice of gamers seems to indicate. Their online gaming was by far the most frequent practice found in our study in comparison with dominant media practices in other lifestyles. As such, this practice seems to compete with a more balanced media lifestyle, as the broadly engaged media omnivores were not involved in online gaming. In other cases it appears the 
technology did not elicit and perhaps even formed an impediment towards engagement, evidenced by the lifestyle of low-frequency media users found in our study. Such findings underscore the added value of investigating media engagement as socially shaped and socially shaping, recognizing that personal preferences may be of influence along with other factors such as those related to the nature of the medium.

There are of course some limitations to the method employed. As in any type of questionnaire research, the categories or 'facets' assumed to be present in each media activity represented abstract properties of engagement, which in reality were undoubtedly much more interwoven. It is questionable, for example, whether one can strictly separate social or entertainment functions from epistemic functions. We therefore believe it is vital that in future research the type of data obtained from studies like ours is combined with more in-depth explorations of media practices, which allows us to more clearly determine the form such practices take and the meaning they have for individual users. But despite its limitations, the design that was drawn upon in the present study proved especially useful to obtain a deeper insight into the variation of media users in a rather large cohort of Dutch youth with full access to digital technology. As such, we believe it provides a promising method for (crossnational) comparisons with different cohorts. It also points to several new avenues for U\&G research to explore while staying to true to the idea that media use is purposive (Rubin, 1994).

\section{New Avenues for Uses \& Gratifications}

The present study points to two important areas for further research, both of which concern a broader conceptualization of media engagement. A first option to further current research, not only $U \& G$, is to start considering mediated and face-to-face communication together. As Ito et al. (2008) have shown, this allows researchers to investigate whether youth follow up on their offline interests and social relationships through their media use. It is important that offline and online are bridged in research because media users do not 
necessarily experience a boundary. For example, by including face-to-face interaction the present study was able to show that networkers stayed connected with known others across online and offline and had a clear preference for the type of technology best - though not fully - able to substitute real-life interaction. Furthermore, considering mediated and face-toface communication together allows researchers to detect when youth do experience a boundary. This appeared to be the case for the low-frequency media users in our study, who showed a low involvement in the broad media spectrum and were perhaps more involved in outdoor activities (e.g., see Trainor, Delfabbro, Anderson \& Winefield, 2010).

A second option to further $U \& G$ research in particular is to move beyond the pleasureseeking motives of mass media that are usually focused on, as others have also suggested (Oliver and Bartsch, 2010; Petrič et al., 2011; Wirth et al., 2012). Due to the new media advent many boundaries that previously existed have been blurred, for example between personal and mass communications and between consumptive and more interactive media uses. The media practices of youth today are multi-faceted and need to be investigated as such. The present study demonstrates a way this can be done, giving equal weight to interpersonal and mass media uses and to entertainment functions as well as applications that are cognitively more demanding. For example, our method allowed us to include activities like watching television or YouTube for fun along with activities such as discussing broader social issues with intimate others through synchronous new media. There is an urgent need to address media applications like the latter, as youth today have a greater opportunity to learn from their (peer-oriented) networks and thus outside of formal institutions like school. It is conceivable that new digital divides arise as a result of these new opportunities.

\section{Differences in Media Lifestyles: Good or Bad?}

The present study not only points to some new perspectives to explore in future research, but it also raises new questions regarding the differences that continue to exist 
between youth in their media-use styles when access to technologies is no longer a basic hindrance. First, it is important to emphasize that the we found few differences between youth from lower and higher educational tracks. Although the sample was not large enough to draw conclusions regarding the entire student population, our study suggests that three out of the four distinguished media lifestyles - networkers, gamers and low-frequency media users - are present more or less equally in all layers of society. This is a significant finding because in The Netherlands educational track is strongly associated with success in school and in later life. It provides further evidence for our argument that differences between youth to a significant extent reflect their personal preferences. In this respect it is interesting to note how persistent gender differences are in our study, suggesting that boys are interested in different things compared to girls.

Assuming media lifestyles are indeed a reflection of individual taste, afforded by particular technologies, what could be the harm in inter-individual differences? In order to do well in the largely print-centred school environment and in order to be prepared for the demands placed by modern society on its citizens, young people need to become wellrounded individuals. Through their out-of-school experiences they may gain familiarity with a broad range of media for different functions within a variety of social settings. In this sense the profile of media omnivores found in our study epitomizes the ideal of a flexible media user attuned to varied circumstances of media engagement (cf. Ravid \& Tolchinsky, 2002). These youth have meaningful interactions with their friends and relatives offline, not only to talk about daily life but also to discuss broader social issues. Furthermore, they are able to bring their offline interests and relationships online and still remain engaged in traditional print-based media. It seems that through their broad and balanced media lifestyle they are optimally prepared to function in different functions and environments, be it at school, at the workplace or in a voting booth. It is possible that their peers, especially the low-frequency 
media users, are less prepared for life at school and beyond. The present study hints at the significance of such differences, as the lifestyle of media omnivores was in fact more often found among youth from higher educational tracks. We therefore believe it is of great importance to investigate the consequences of less diversified media lifestyles in future research, for which this study could provide a theoretical and methodological basis. 


\section{References}

Boase, J., Horrigan, J.B., Wellman, B., \& Rainie, L. (2006). The strength of internet ties (Report of the Pew Internet \& American Life Project). Retrieved October 2, 2012, from http://www.pewinternet.org/ /media//Files/Reports/2006/PIP_Internet_ties.pdf.pdf

Bolter, D. J. \& Grusin R., (1999). Remediation: Understanding new media. Cambridge, MA: MIT Press.

Boneva, B. S., Quinn, A., Kraut, R. E., Kiesler, S., \& Shklovski, I. (2006). Teenage communication in the instant messaging era. In R. Kraut, M. Brynin \& S. Kiesler (Eds.), Computers, phones, and the internet: Domesticating information technology (pp. 612-672). New York: Oxford University Press.

Brozo, W.G., Shiel, G., \& Topping, K. (2007). Engagement in reading: Lessons learned from three PISA countries. Journal of Adolescent \& Adult Literacy, 51(4), 304-315. doi:10.1598/JAAL.51.4.2

Buckingham, D. (Ed.) (2008). Youth, Identity, and Digital Media. Cambridge: MIT Press. Centraal Bureau voor de Statistiek (2009). Jaarboek onderwijs in cijfers. Rotterdam: TelDesign. OBT bv, Den Haag.

Duimel, M., \& De Haan, J. (2007). Nieuwe links in het gezin: De digitale leefwereld van tieners en de rol van hun ouders. Den Haag: Sociaal en Cultureel Planbureau.

Eastin, M.S., Greenberg, B.S., \& Hofschire, L. (2006). Parenting the Internet. Journal of Communication, 56(3), 486-504. doi:10.1111/j.1460-2466.2006.00297.x.

Facer, K. \& Furlong, R., (2001). Beyond the myth of the 'cyberkid': Young people at the margins of the information revolution. Journal of Youth Studies, 4(4), 451-469. doi:10.1080/13676260120101905. 
Fielding, A.H. (2007). Cluster and classification techniques for the biosciences. Cambridge: Cambridge University Press.

Flanagin, A.J., Metzger, M.J. (2001). Internet use in the contemporary media environment. Human Communication Research, 27(1), 153-181. doi:10.1111/j.14682958.2001.tb00779.x

Guttman, R., \& Greenbaum, C. W. (1998). Facet theory: Its development and current status. European Psychologist, 3(1), 13-36. doi:10.1027/1016-9040.3.1.13.

Herring, C. (2008). Questioning the generational divide: Technological exoticism and adult constructions of online youth identity. In A. D. Buckingham (Ed.), Youth, identity and digital media. Cambridge, MA: MIT Press.

Heath, S. B. (1980). The functions and uses of literacy. Journal of Communication, 30(1), 123-133. doi: 10.1111/j.1460-2466.1980.tb01778.x.

Hine, C. (2005). Virtual methods and the sociology of cyber-social-scientific knowledge. In C. Hine (Ed.), Virtual methods. Issues in social research on the Internet (pp.1-13). Oxford: Berg.

Ito, M., Horst, H., Bittanti, M., Boyd, D., Herr-Stephenson, B., Lange, P.G., .. Tripp, L. (2008). Living and learning with new media: Summary of findings from the Digital Youth Project (Report from the John D. and Catherine T. MacArthur Foundation). Retrieved October 2, 2012, available from http://www.macfound.org/

Katz, E. (1959). Mass communications research and the study of popular culture: An editorial note on a possible future for this journal. Studies in Public Communication, (2), 1-6.

Leino, K., Linnakylä, P. \& Malin, A. (2004). Finnish students' multiliteracy profiles. Scandinavian Journal of Educational Research, 48(3), 251-270. $\underline{\text { doi:10.1080/00313830410001695727 }}$

Lister, M., Dovey, J., Giddings, S., Grant, I. \& Kelly, K. (2003). New media: A critical 
introduction. London and New York: Routledge.

Livingstone, S. \& Bovill, M. (1999). Young people, new media: Report of the research project Children, Young People and the Changing Media Environment. Research report, Department of Media and Communications, London School of Economics and Political Science. Retrieved October 2, 2012, from http://eprints.lse.ac.uk/21177/.

Oliver, M.B., \& Bartsch, A. (2010). Appreciation as audience response: Exploring entertainment gratifications beyond hedonism. Human Communication Research, 36(1), 53-81. doi:10.1111/j.1468-2958.2009.01368.x

Petrič, G., Petrovčič, A. \& Vehovar, V. (2011). Social uses of interpersonal communication technologies in a complex media environment. European Journal of Communication, 26(2), 116-132. doi:10.1177/0267323111402654

Rantanen, T. (2005). The media and globalization. London: Sage Publications.

Ravid, D. \& Tolchinsky, L. (2002). Developing linguistic literacy: A comprehensive model. Journal of Child Language, 29, 417-447. doi:10.1017/S0305000902005111

Rideout, V.J., Foehr, U.G., Roberts, D.F. (2010). Generation $\mathrm{M}^{2}$ : Media in the lives of 8- to 18-year-olds. A Kaiser Family Foundation Study. Retrieved October 2, 2012, from http://www.kff.org/entmedia/upload/8010.pdf

Roberts, D.F. \& Foehr, U.G. (2008). Trends in media use. The Future of Children, 18(1), 1137. Retrieved October 2, 2012, from http://futureofchildren.org/futureofchildren/publications/docs/18_01_02.pdf

Rubin, A.M. (1994). Media uses and effects: A uses-and-gratifications perspective. In J. Zillman \& D. Bryant (Eds.), Media effects: Advances in theory and research (pp. 571601). London: Erlbaum. 
Trainor, S., Delfabbro, P. H., Winefield, A. H., \& Anderson, S. (2010). Leisure activities and adolescent psychological well-being. Journal of Adolescence, 33(1), 173-186. doi:10.1016/j.adolescence.2009.03.013.

Ünlüsoy, A., De Haan, M., Leseman, P.P.M., \& Van Kruistum, C. (2010). Gender differences in adolescents' out-of-school literacy practices: A multifaceted approach. Computers \& Education, 55(2), 742-751, doi:10.1016\%2Fj.compedu.2010.03.007.

Van den Beemt, A. (2010). Interactive media practices of young people: Origins, backgrounds, motives and patterns (Doctoral dissertation). Retrieved October 2, 2012, from http://igitur-archive.library.uu.nl/dissertations/2010-1118-200300/beemt.pdf

Van Kruistum, C., Leseman, P.P.M., \& De Haan, M. (2014). Literacy engagement patterns of youth with old and new media. Manuscript submitted for publication.

Wirth, W., Hofer, M., \& Schramm, H. (2012). Beyond pleasure: Exploring the eudaimonic entertainment experience. Human Communication Research, 38(4), 406-428. doi: 10.1111/j.1468-2958.2012.01434.x.

Williams, R. (1974). Television: Technology and cultural form. Glasgow: Fontana. 
Table 1

Frequency/Duration of Engagement in Media Practices with Comparisons between Lower-Higher Educational Tracks and Boys-Girls

\begin{tabular}{|c|c|c|c|c|c|c|c|c|c|c|c|c|c|c|}
\hline \multirow[b]{3}{*}{ Media practices } & & & \multicolumn{4}{|c|}{ Track } & \multirow{4}{*}{$\begin{array}{r}F(1,501) \\
9.07^{* *}\end{array}$} & \multirow{4}{*}{$\begin{array}{r}\text { Partial } \eta^{2} \\
.02\end{array}$} & \multicolumn{4}{|c|}{ Gender } & \multirow{4}{*}{$\frac{F(1,501)}{30.07^{* * *}}$} & \multirow{4}{*}{$\begin{array}{r}\text { Partial } \eta^{2} \\
.06\end{array}$} \\
\hline & \multicolumn{2}{|c|}{ Total } & \multicolumn{2}{|c|}{ Lower } & \multicolumn{2}{|c|}{ Higher } & & & \multicolumn{2}{|c|}{ Boys } & \multicolumn{2}{|c|}{ Girls } & & \\
\hline & $M$ & $S D$ & $M$ & $S D$ & $M$ & $S D$ & & & $M$ & $S D$ & $M$ & $S D$ & & \\
\hline A. F, small, SE & 4.56 & $(1.22)$ & 4.41 & $(1.32)$ & 4.74 & $(1.07)$ & & & 4.28 & $(1.27)$ & 4.86 & $(1.08)$ & & \\
\hline B. F, small, EP & 2.63 & $(1.38)$ & 2.36 & $(1.33)$ & 2.93 & $(1.38)$ & $21.86^{* * * *}$ & .04 & 2.57 & $(1.41)$ & 2.69 & $(1.36)$ & .88 & .00 \\
\hline C. F, large, SE & 2.21 & $(.77)$ & 2.20 & $(.80)$ & 2.23 & $(.73)$ & .25 & .00 & 2.16 & $(.81)$ & 2.28 & $(.72)$ & 3.18 & .01 \\
\hline D. F, large, EP & 1.37 & (.69) & 1.25 & $(.62)$ & 1.50 & $(.75)$ & $15.61 * * *$ & .03 & 1.27 & $(.64)$ & 1.47 & $(.73)$ & $10.24 * *$ & .02 \\
\hline E. P, small, SE & 1.72 & $(.73)$ & 1.69 & $(.80)$ & 1.75 & $(.64)$ & $.96^{*}$ & .00 & 1.54 & $(.66)$ & 1.90 & $(.75)$ & $32.92 * * *$ & .06 \\
\hline F. P, large, SE & 2.95 & $(1.11)$ & 2.70 & $(1.15)$ & 3.25 & $(.99)$ & $32.60 * * *$ & .06 & 2.72 & $(1.16)$ & 3.20 & $(1.00)$ & $24.44 * * *$ & .05 \\
\hline G. P, large, EP & 2.57 & $(.99)$ & 2.52 & $(1.03)$ & 2.63 & $(.94)$ & 1.62 & .00 & 2.47 & $(1.05)$ & 2.68 & $(.91)$ & $5.59 *$ & .01 \\
\hline H. SNM, small, SE & 3.48 & $(1.33)$ & 3.69 & $(1.26)$ & 3.24 & $(1.37)$ & $15.11 * * *$ & .03 & 3.25 & $(1.28)$ & 3.73 & $(1.34)$ & $17.36^{* * *}$ & .03 \\
\hline I. SNM, small, EP & 2.10 & $(1.02)$ & 2.17 & $(1.07)$ & 2.02 & $(.95)$ & 2.70 & .01 & 1.98 & $(1.06)$ & 2.23 & $(.96)$ & $8.05 * *$ & .02 \\
\hline J. SNM, large, SE & 2.72 & $(2.04)$ & 2.99 & $(2.09)$ & 2.42 & $(1.93)$ & $10.27 * *$ & .02 & 3.46 & $(2.21)$ & 1.93 & $(1.47)$ & $82.72 * * *$ & .14 \\
\hline K. ANM, small, SE & 3.67 & $(1.25)$ & 3.64 & $(1.27)$ & 3.71 & $(1.23)$ & .36 & .00 & 3.33 & $(1.25)$ & 4.04 & $(1.14)$ & $42.95^{* * *}$ & .08 \\
\hline L. ANM, large, SE & 3.72 & $(.94)$ & 3.69 & $(.98)$ & 3.75 & $(.89)$ & .49 & .00 & 3.89 & $(1.01)$ & 3.53 & $(.83)$ & $18.35^{* * *}$ & .04 \\
\hline M. ANM, large, EP & 2.67 & $(.85)$ & 2.70 & $.96)$ & 2.63 & $(.70)$ & 1.07 & .00 & 2.54 & $(.89)$ & 2.80 & $(.78)$ & $11.65^{* *}$ & .02 \\
\hline
\end{tabular}

Note F = face-to-face; $\mathrm{P}=$ print $; \mathrm{SNM}=$ synchronous new media $; \mathrm{ANM}=$ asynchronous new media; small = small social distance $;$ large = large social distance; $\mathrm{SE}=$ social-

entertainment function; $\mathrm{EP}=$ epistemic function. $* p<.05 . * * p<.01 . * * * p<.001$. 
Table 2

Frequency/Duration of Engagement in Media Practices and Standard Deviations for Each Cluster

\begin{tabular}{|c|c|c|c|c|c|c|c|}
\hline \multirow[b]{2}{*}{ Media practices } & $\begin{array}{c}\text { 1: Omnivores } \\
(n=165)\end{array}$ & $\begin{array}{c}\text { 2: Networkers } \\
(n=87)\end{array}$ & $\begin{array}{c}\text { 3: Gamers } \\
(n=146)\end{array}$ & $\begin{array}{c}\text { 4: Low users } \\
\quad(n=105)\end{array}$ & \multicolumn{3}{|c|}{ Differences } \\
\hline & $M S D$ & $M S D$ & $M S D$ & $M S D$ & $F(3,499)$ & Partial $\eta^{2}$ & Tukey \\
\hline A. F, small, SE & $5.10(.94)$ & $4.91(.98)$ & $4.43(1.27)$ & $3.60(1.11)$ & $44.46^{*}$ & .21 & $1,2>3>4$ \\
\hline B. F, small, EP & $3.83(1.06)$ & $1.75(.82)$ & $2.45(1.35)$ & $1.71(.75)$ & $116.92 *$ & .41 & $1>3>2,4$ \\
\hline C. F, large, SE & $2.55(.73)$ & $2.22(.66)$ & $2.15(.82)$ & $1.78(.58)$ & $25.29 *$ & .13 & $1>2,3>4$ \\
\hline D. F, large, EP & $1.61(.79)$ & $1.32(.62)$ & $1.29(.73)$ & $1.13(.69)$ & $11.92 *$ & .07 & $1>2,3,4$ \\
\hline E. P, small, SE & $1.98(.77)$ & $1.69(.66)$ & $1.65(.76)$ & $1.41(.48)$ & $15.24 *$ & .08 & $1>2,3>4$ \\
\hline F. P, large, SE & $3.57(.89)$ & $2.82(1.01)$ & $2.96(1.10)$ & $2.08(.89)$ & $50.80 *$ & .23 & $1>2,3>4$ \\
\hline G. P, large, EP & $3.16(.87)$ & $2.24(.76)$ & $2.51(.99)$ & $2.00(.83)$ & $43.32 *$ & .21 & $1>3>4 ; 1>2$ \\
\hline H. SNM, small, SE & $3.09(1.09)$ & $4.91(.95)$ & $3.47(1.38)$ & $2.92(1.00)$ & $60.60 *$ & .27 & $2>3>1,4$ \\
\hline I. SNM, small, EP & $2.23(1.01)$ & $2.32(.87)$ & 2.08 (1.09) & $1.76(.96)$ & $6.41 *$ & .04 & $1,2>4$ \\
\hline J. SNM, large, SE & $1.53(.83)$ & $1.48(.76)$ & 5.51 (1.09) & $1.73(1.15)$ & $566.64 *$ & .77 & $3>1,2,4$ \\
\hline K. ANM, small, SE & $3.84(1.12)$ & $4.66(.83)$ & $3.47(1.27)$ & $2.86(1.07)$ & $44.33 *$ & .21 & $2>1>3>4$ \\
\hline L. ANM, large, SE & $3.78(.87)$ & $3.45(.78)$ & $4.23(.86)$ & $3.13(.86)$ & $37.86^{*}$ & .19 & $3>1>2>4$ \\
\hline M. ANM, large, EP & $2.89(.72)$ & $2.78(.84)$ & $2.73(.98)$ & $2.14(.60)$ & $20.46^{*}$ & .11 & $1,2,3>4$ \\
\hline
\end{tabular}

Note. $\mathrm{F}$ = face-to-face; $\mathrm{P}$ = print; $\mathrm{SNM}=$ synchronous new media; $\mathrm{ANM}=$ asynchronous new media; small = small social distance;

large = large social distance $\mathrm{SE}=$ social-entertainment function; $\mathrm{EP}=$ epistemic function. $* p<.001$. 
Table 3

Number of Youth in Each Cluster

\begin{tabular}{|c|c|c|c|c|c|c|}
\hline & 1: Omnivores & 2: Networkers & 3: Gamers & 4: Low users & & \\
\hline & $n \%$ & $n \%$ & $n \%$ & $n \%$ & $\chi^{2}(3)$ & $V$ \\
\hline \multicolumn{7}{|l|}{ Track } \\
\hline Lower & $6338.8 * *$ & 4956.3 & 9263.0 & 6360.0 & \multirow{2}{*}{$22.88 * * *$} & \multirow{2}{*}{.21} \\
\hline Higher & $10261.8 * *$ & $38 \quad 43.7$ & 5437.0 & $42 \quad 40.0$ & & \\
\hline \multicolumn{7}{|l|}{ Gender } \\
\hline Boy & $6036.4 * *$ & $1820.7 * * *$ & $11276.7 * * *$ & $7066.7^{*}$ & \multirow{2}{*}{$95.04 * * *$} & \multirow{2}{*}{.43} \\
\hline Girl & $10563.6^{* *}$ & $6979.3 * * *$ & $3423.3^{* * *}$ & $3533.3 *$ & & \\
\hline Total & 165 & 87 & 146 & 105 & & \\
\hline
\end{tabular}

$* p<.05 . * * p<.01 . * * * p<.001$. 

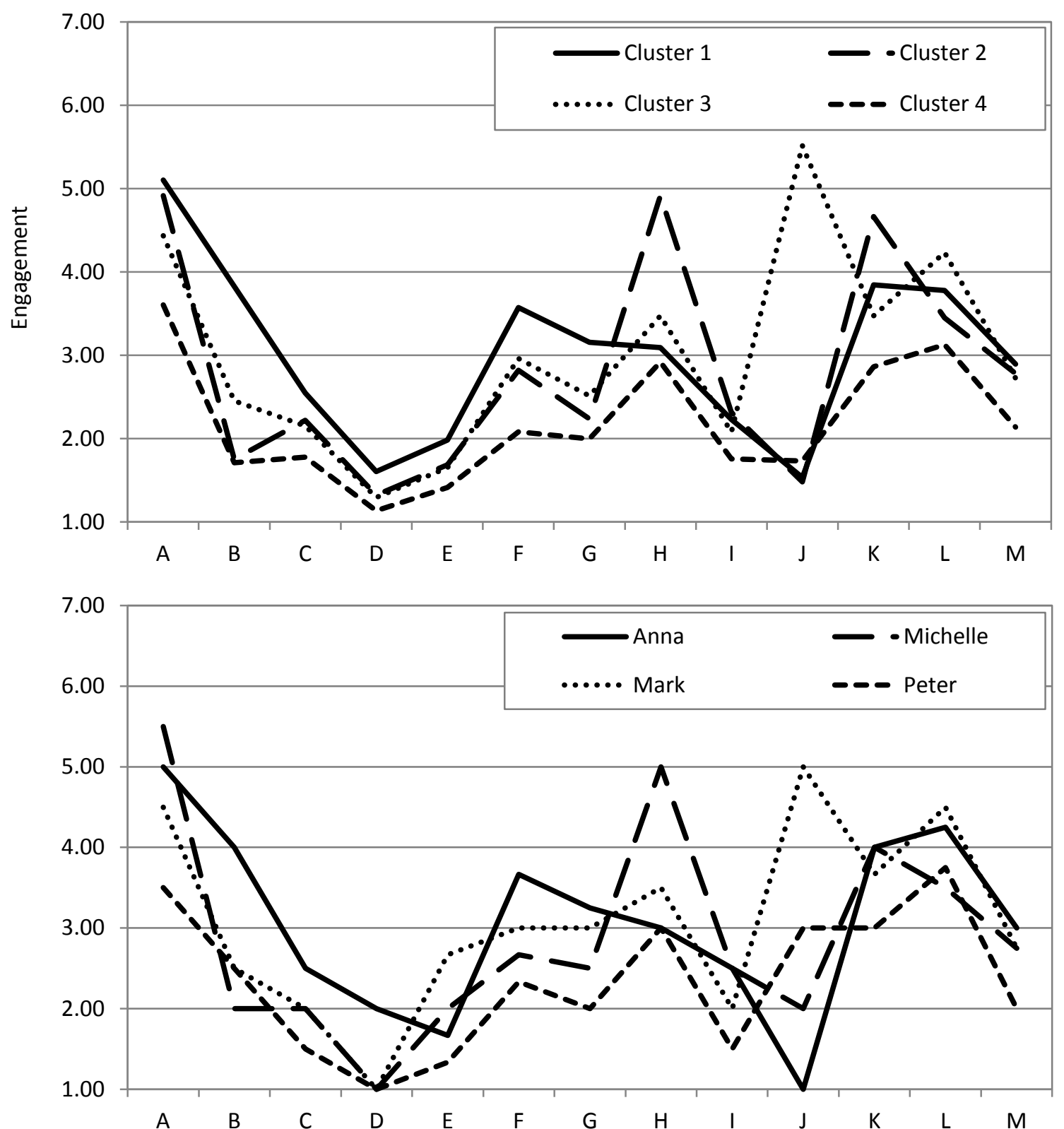
A: face-to-face + small SD + social-entertainment
$\mathrm{H}$ : sync NM + small SD + social-entertainment
B: face-to-face + small SD + epistemic
I: sync NM + small SD + epistemic
C: face-to-face + large SD + social-entertainment
J: sync NM + large SD + social-entertainment
D: face-to-face + large SD + epistemic
$\mathrm{K}:$ async $\mathrm{NM}+$ small $\mathrm{SD}+$ social-entertainment
$\mathrm{E}:$ print + small SD + social-entertainment
L: async NM + large SD + social-entertainment
$\mathrm{F}$ : print + large SD + social-entertainment
M: async NM + large SD + epistemic
G: print + large SD + epistemic

Figure 1. Mean engagement for each cluster (above) and prototypical members (below) 